\title{
TERRAS RARAS: CONSIDERAÇÕES SOBRE O PLANALTO DE POÇOS DE CALDAS, MG NO NOVO CENÁRIO MUNDIAL
}

\author{
A. D. V. GOUVEA, F. C. NAVARRO e C. D. ROVERI \\ Universidade Federal de Alfenas - MG \\ almir.donizette@gmail.com
}

Artigo submetido em novembro/2013 e aceito em agosto/2014

DOI: $10.15628 /$ holos.2014.1810

\section{RESUMO}

A importância dos minerais de terras raras, considerados "materiais da terceira onda", se deve a sua relação com o desenvolvimento tecnológico. A China por muito tempo dominou a produção e vendas no mercado mundial, adotando nos últimos anos severas medidas protecionistas que acabaram por forçar diversos países a optar por outras formas de suprimento para suas demandas. A necessidade de procurar novas fontes de minerais estratégicos levou ao desenvolvimento ou retomada de programas de exploração em diversas áreas. Dentre essas, destaca-se o Planalto de Poços de Caldas - MG, que corresponde a um depósito laterítico desenvolvido sobre um complexo alcalino intrusivo em domínios de embasamento cristalino. Nesse contexto geológico observam-se comportamentos distintos quanto aos processos de laterização e/ou oxidação que ocasionam a lixiviação de certos elementos e enriquecimento residual dos menores móveis, podendo formar um depósito econômico dependendo das condições locais. São apresentados dados oriundos de extensa revisão bibliográfica acerca do potencial geológico deste depósito e propõe-se a aplicação de técnicas de baixo custo para os trabalhos prospectivos no maciço.

PALAVRAS-CHAVE: Terras raras, materiais da terceira onda, Planalto de Poços de Caldas - MG.

\section{RARE EARTH ELEMENTS: CONSIDERATIONS ON THE POÇOS DE CALDAS PLATEAU IN THE NEW WORLD SCENE}

\begin{abstract}
The importance of rare earths minerals, considered "third wave materials," is due to their relationship with the technological development. China dominated the supply and marketing in the world for a long time and in recent years has adopted strong protection practices that naturally lead many countries to search for other supply sources for their demand. The need to seek new sources of these strategic minerals has led to the development of exploration programs in areas such as the Poços de Caldas Plateau Minas Gerais state. This is a lateritic deposit developed on an alkaline complex that intrudes
\end{abstract}

in a crystalline basement domain with different responses to laterization and/or oxidation processes resulting in the intense leaching of certain elements and the residual enrichment of minor immobile elements that may form an economical deposit depending of local conditions. Based on literature review we point out the potential of the lateritic deposits of Poços de Caldas Minas Gerais state as an important target for these minerals taking into account the challenges of processing them in industrial plants.

KEYWORDS: Rare earths elements, third wave materials, Poços de Caldas - MG Plateau. 


\section{INTRODUÇÃO}

Os chamados "elementos de terras raras" receberam esse nome porque seus óxidos insolúveis apresentavam aspecto terroso e como seu estudo foi realizado no final do século dezoito eram considerados como sendo raros. No entanto, sabemos que isso é errôneo, já que se encontram amplamente distribuídos na crosta terrestre, porém em pequenas concentrações, e em diversos minerais (ABRÃO, 1994).

Os elementos de terras raras (ETR) ou terras raras (TR), de acordo com o uso corrente em geoquímica, pertencem ao grupo III-B na tabela periódica e compreendem 15 elementos: lantânio $(\mathrm{La})$, cério $(\mathrm{Ce})$, praseodímio $(\mathrm{Pr})$, neodímio $(\mathrm{Nd})$, promécio $(\mathrm{Pm})$, samário $(\mathrm{Sm})$, európio $(\mathrm{Eu})$, gadolínio (Gd), térbio (Tb), disprósio (Dy), hólmio (Ho), érbio (Er), túlio $(T m)$, itérbio $(\mathrm{Yb})$ e lutécio (Lu), com número atômico situado entre 57 e 71. Segundo a IUPAC (1968), o termo deveria fazer menção aos lantanídeos juntamente com o lantânio, escândio (Sc) e ítrio (Y) por causa da semelhança nas suas propriedades químicas e físicas.

A semelhança nas propriedades químicas é devido às suas configurações eletrônicas. Apenas os elementos escândio $(\mathrm{Sc})$ e ítrio $(\mathrm{Y})$ não derivam da configuração do gás nobre xenônio $(\mathrm{Xe})$, logo os demais possuem o preenchimento sequencial da camada $4 \mathrm{f}$.

Segundo Neumann et al. (1966), a estrutura mineral desempenha o papel principal para captura de íons específicos de ETR durante sua formação. A localização dos elementos de terras raras na rede cristalina favorece a seleção de determinados elementos de acordo com seu número de coordenação, já que os sítios cristalinos que apresentam um número alto (10-12), são seletivos para o $\mathrm{Ce}$, os de valores intermediários (7-9), para os elementos de terras raras leves e pesados e os de baixo número de coordenação (6) para o Y. As condições genéticas que definem a paragênese mineral desempenham papel fundamental na distribuição dos elementos de terras raras, sendo estes introduzidos como minerais acessórios por isomorfismo no mineral principal ou inclusão nas fendas e superfícies após sua formação, gerando os chamados minerais portadores de terras raras.

Os minerais de terras raras estão amplamente distribuídos na crosta terrestre em diferentes concentrações podendo ser encontrados em diversos ambientes geológicos, de acordo com a associação mineral. Existem oito tipos de depósitos no qual podem se formar: carbonatíticos, ígneo alcalino, óxido de ferro - cobre - ouro (IOCG), hidrotermais, pegmatitos, "placers", íon adsorvidos em argilas e laterítico.

Os minerais de minério para ETR com os maiores teores conhecidos são bastenasita, monazita e xenotímio. Existem ainda minerais com concentrações menores, tais como gadolinita, loparita, samarkita, allanita, fergusonita, euxenita e argilas lateríticas, que permitem aproveitamento econômico.

Com o avanço de tecnologia a busca por minérios de terras raras se torna cada vez mais importante, devido à melhoria de desempenho em algumas propriedades (mecânicas, elétricas, magnéticas e óticas, por exemplo) que os materiais passam a apresentar. Por conta dessa tecnologia foi possível reduzir significativamente o tamanho de equipamentos eletrônicos e aumentar a eficiência de muitos tipos de ligas metálicas importantes para a indústria espacial, entre outras muitas aplicações de uso corrente e diário que passam despercebidas para a maioria das pessoas. 
Como exemplo de ampla aplicação industrial cita-se o caso dos imãs permanentes. Produzidos com neodímio ( $\mathrm{Nd}$ ) combinado ao ferro e boro $\left(\mathrm{Nd}_{2} \mathrm{Fe}_{14} \mathrm{~B}\right)$, esses imãs são capazes de manter um campo magnético por tempo indeterminado. Fabricados a partir de material magnetizado não precisam de corrente elétrica externa para acionar o magnetismo, devido à remanência, e só são desmagnetizados por sujeiras, vibrações, corrosão ou interferência de campo magnético. A incorporação do elemento Neodímio no processo traz como vantagem, em comparação aos outros tipos de imãs, maior resistência à desmagnetização por campos magnéticos externos (alto fator de coercividade), maior permanência da magnetização (alto fator de remanência) e maior força magnética (alta intensidade do campo magnético).

\section{DEMANDA MUNDIAL}

Segundo Petrick (1973), os elementos de terras raras têm sua importância por poderem ser usados como dopantes em diversas aplicações tecnológicas. Por conta disso é importante a pesquisa e o desenvolvimento de tecnologia de separação, purificação e utilização, visando valorização dos recursos minerais.

Devido às características geoquímicas semelhantes os ETR sempre se formam associados na natureza. Por essa razão o aumento da produção em um desses elementos significa em aumento de outros. Essa peculiaridade também afeta os processos de extração e concentração, dificultando a obtenção de óxidos com a concentração e pureza necessários a alguns processos industriais.

As principais reservas de terras raras estão localizadas na China, Estados Unidos, CEI e Austrália, no entanto, ainda podemos encontrar reservas na Índia, Vietnã, África do Sul, Groelândia, Canadá e Europa (Figuras 1 e 2).

\section{PRODUÇĀo E DEMANDA EM 2009 EM TONELADAS}

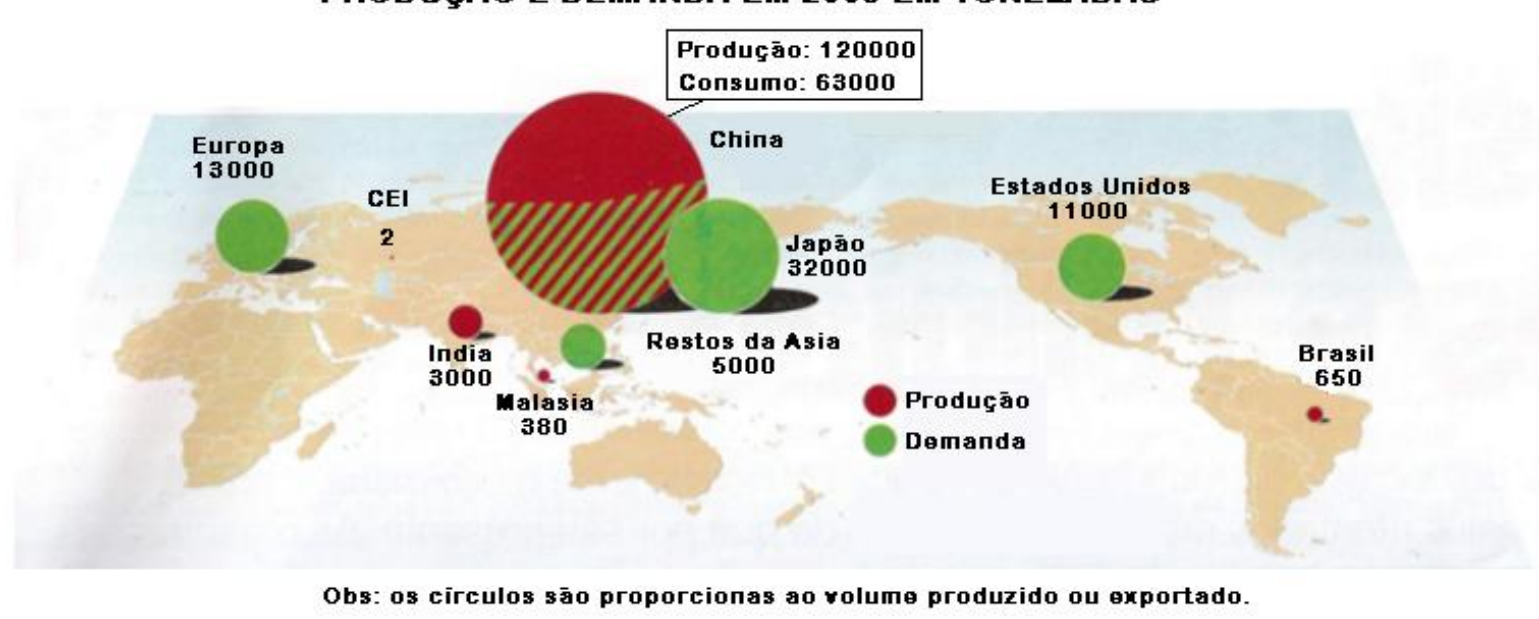

Figura 1: Produção e demanda de terras raras em 2009 em toneladas. Fonte: Lapido-Loureiro, 2011 (Adaptado). 
RESERYA3 CONFIRMADA3 EM SETEMBRO DE 2010 EM MILHŌES DE TONELADA3

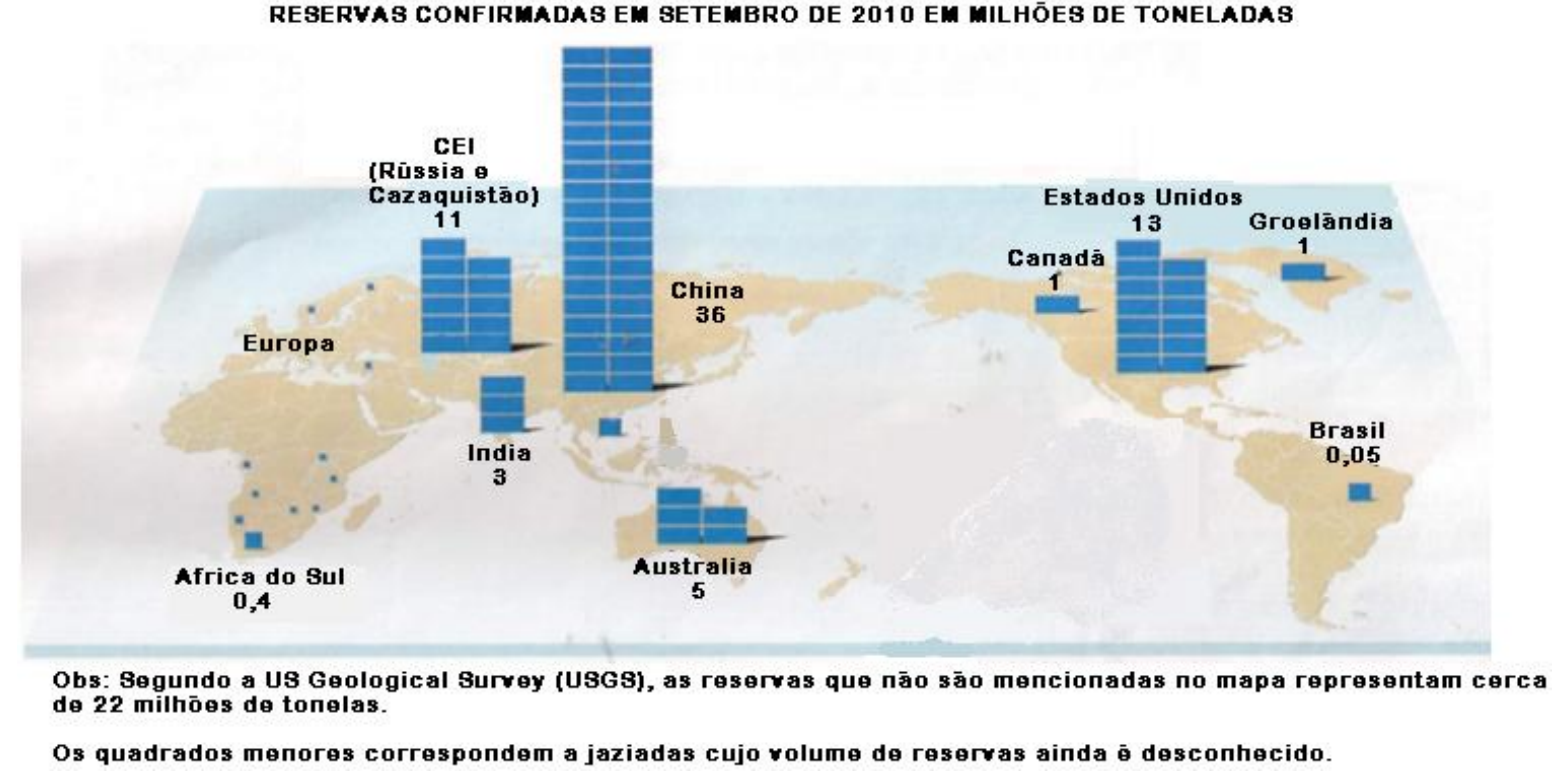

Figura 2: Reservas confirmadas em setembro de 2010 representadas em milhões de toneladas. Fonte: Lapido-Loureiro, 2011 (Adaptado).

De acordo com as pesquisas de Tse (2011) e Humphries (2012), a China desempenhou um papel importante no contexto das terras raras. Em 1990, o governo chinês declarou as terras raras como sendo minerais estratégicos e que deveriam ser protegidos, criando limitações para os investidores estrangeiros, cotas de produção ajudando a controlar a produção, exportação, aumentar a receita e regulamentar as indústrias de minerais. Na mesma década o governo chinês incentivou as empresas locais a exportar seus produtos através do reembolso do imposto sobre valor agregado que os produtores pagam sobre produtos exportados gerando baixo custo de produção e a queda dos preços mundialmente.

No início de 2000, devido ao aumento do consumo interno, houve redução do desconto de exportação para muitos produtos estratégicos. Em 2005, o desconto sobre exportação de terras raras foi eliminado, e o comércio de concentrado de terras-raras foi banido. Em 2006 a taxa de exportação teve aumento de 31\% no preço das matérias primas de terras raras (TSE, 2011).

Em 2007, para restringir a exportação o governo chinês introduziu um imposto de exportação nos produtos de terras raras que consomem grandes quantidades de energia durante a fabricação a fim de proteger a produção doméstica de minerais estratégicos. Por esse motivo a demanda do mercado internacional passou a superar a oferta gerando instabilidade econômica no seguimento e altas exageradas dos preços, cenário que deve ser revertido a partir de 2014.

Todas as medidas protecionistas da China acabaram favorecendo a pesquisa mineral pela busca de fontes em países diferentes.

\section{SITUAÇÃO NO BRASIL}

Segundo Abreu (1991), as reservas brasileiras correspondem a aproximadamente 1\% da produção mundial. 
Em 2010 o Brasil importou compostos químicos e produtos manufaturados contendo elementos de terras raras no valor de US\$14,1 milhões (FOB) originados dos seguintes países e produtos (ANDRADE, 2011):

- Estados Unidos (88\%), bens primários;

- China (82\%), Estados Unidos (5\%), Bulgária (7\%), Austrália (2\%) e Bélgica (2\%), produtos manufaturados;

- China (93\%), Estados Unidos (2\%), Espanha (2\%) e França (2\%), compostos químicos.

- As exportações no mesmo ano foram de compostos químicos e produtos manufaturados no montante de US\$ 1,4 milhão (FOB):

- Compostos químicos para a Espanha (99\%);

- Produtos manufaturados para o Reino Unido (27\%), Canadá (21\%), Angola (21\%), Estados Unidos (17\%) e Países Baixos (4\%).

O fluxo comercial brasileiro considerando importações, exportações e consumo de terras raras mostra a necessidade do Brasil em investir em tecnologias para melhorar a produção interna suprindo a necessidade de terras raras através da busca por novas reservas que contenham esses minérios.

As principais aplicações dos compostos de terras raras no Brasil atualmente são: composição e polimentos de vidros e lentes especiais, catalisadores de automóveis, refino de petróleo, fósforo para tubos catódicos de televisores, imãs permanentes para motores miniaturizados, ressonância magnética nuclear, cristais geradores de laser, supercondutores e absorvedores de hidrogênio (ANDRADE, 2011).

Segundo Lapido - Loureiro (1994), embora no Brasil toda a produção de terras raras fosse oriunda de depósitos aluvionares marinhos, as maiores reservas com teores detectados encontram-se em solos ferralíticos ou crosta de alteração, geralmente associados a outros minérios como apatita, anatásio, pirocloro, cassiterita e fluorita.

Os solos ferralíticos, resultantes do intemperismo de complexos alcalino contendo lateritos mineralizados, oriundos principalmente do cenozóico devido à dificuldade de manter uma formação superficial inalterada por muito tempo, podem constituir a maior fonte de elementos de terras raras do mundo. A grande dificuldade para tornar viável a extração do minério é encontrar meios para seu beneficiamento.

Esses depósitos residuais são derivados de prolongado intemperismo tropical que leva ao colapso de muitas rochas formadoras de sais minerais com preservação do mineral primário portador do elemento de interesse por ser relativamente resistente ao processo. Certos elementos (por exemplo, cálcio e magnésio) são lixiviados, com enriquecimento residual de outros elementos menos móveis (por exemplo, ferro e alumínio), como é o caso dos depósitos de bauxita, minério de alumínio.

Levando em conta determinadas condições e de acordo com o local onde a rocha matriz é enriquecida em ETR, tais como carbonatitos, os elementos de terras raras podem ser enriquecidos para formar um depósito econômico. Intemperismo químico de carbonatitos provoca a dissolução de calcita, dolomita e, em menor proporção, da apatita. Os ETR liberados desses minerais podem 
ser incorporados em novos minerais supergênicos, geralmente fosfatos, incluindo em minerais como a monazita, que são importantes na formação dos depósitos, pois são normalmente de alta qualidade, contendo $10 \%$ a $25 \%$ de óxidos de terras raras.

Segundo Lapido-Loureiro (1994), os métodos de prospecção de terras raras devem compreender o estudo de seus depósitos baseando-se no conhecimento geológico e as especificidades físicas e geoquímicas dos minerais de ETR localizados na área estudada, com base no mapeamento geológico estrutural; levantamento radiométrico (concentração de tório e urânio) e geoquímico; rede de amostragem superficial; abertura, mapeamento e amostragem de poços considerando as partes mineralógicas e químicas; interpretação de dados para determinação da ocorrência dos minerais com foco para os minerais de minério de terras raras e ensaios de extração e beneficiamento para que se possa avaliar a viabilidade econômica da reserva.

\section{PLANALTO DE POÇOS DE CALDAS}

O Platô de Poços de Caldas (MAPC) localiza-se na divisa dos estados de Minas Gerais e São Paulo, a aproximadamente $300 \mathrm{~km}$ da cidade de São Paulo. O maciço, de formato aproximado circular, possui uma área de $750 \mathrm{~km}^{2}$, com diâmetro de cerca de $35 \mathrm{~km}$, representado por um planalto montanhoso de pequena unidade morfoestrutural estabelecido numa chaminé de rochas eruptivas alcalinas de configuração circular. A altitude média do platô é de $1300 \mathrm{~m}$, bordejado por diques anelares, oriundos de ascensão do magma nefelínico na periferia do maciço e de fendas circulares, de 1500 a 1650 m de altitude. A cidade de Poços de Caldas, com aproximadamente 170.000 habitantes, no limite norte da cratera, é um importante centro hidrotermomineral do Brasil e apresenta também importantes atividades de mineração de bauxita e argila. As rochas constituintes são de filiação alcalina com idade Mesozóica-Cenozóica. O maciço, de natureza intrusiva, tem como embasamento cristalino as rochas Arqueanas, constituídas na maioria por gnaisses, migmatitos e granulitos. As rochas mais abundantes são nefelina-sienitos, tinguaítos, fonólitos e foiaítos (Figura 3).

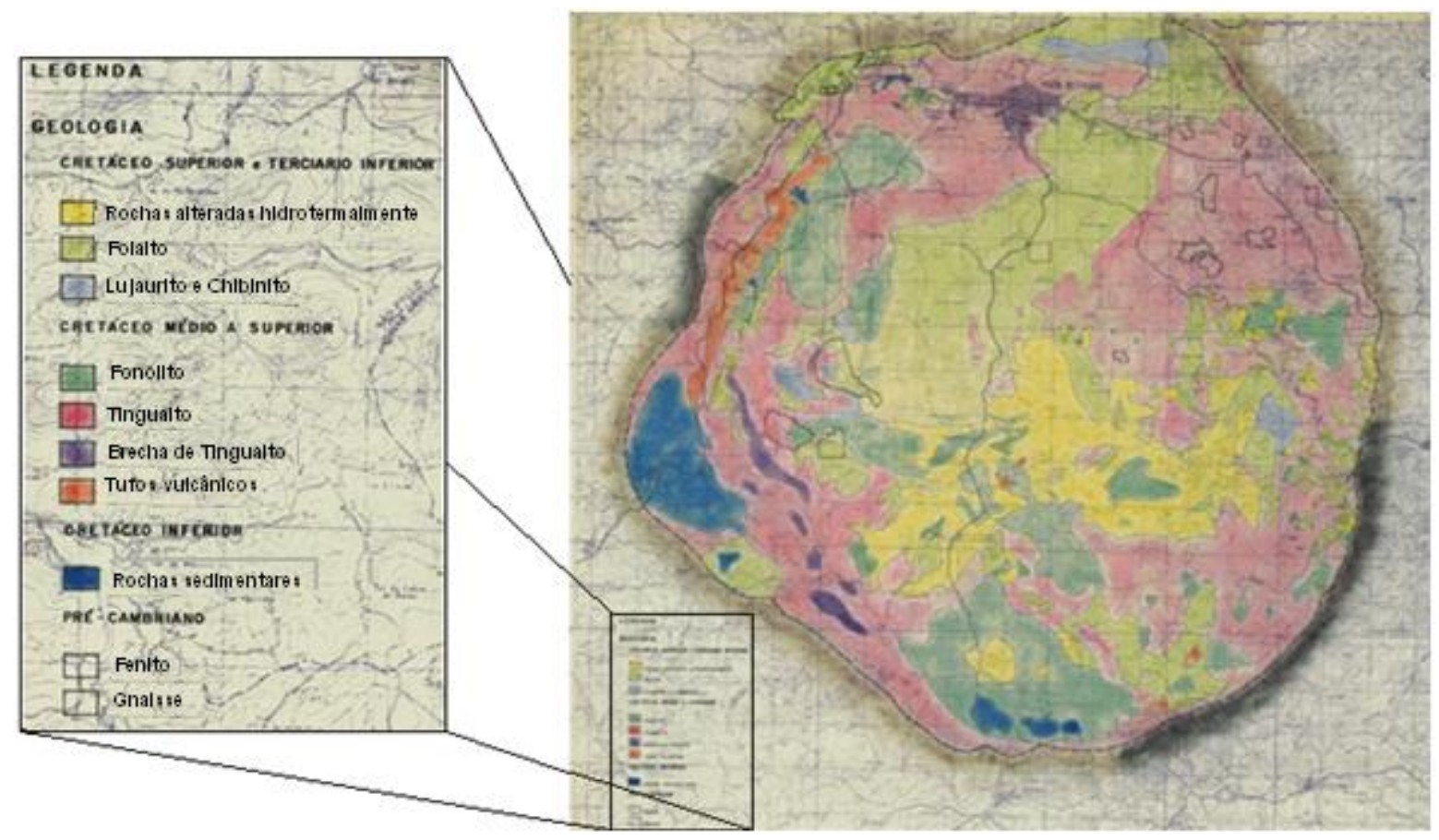

Figura 3: Representação geológico estrutural do Maciço Alcalino Poços de Caldas. Fonte: INB. 
Os diversos tipos litológicos de origem alcalina podem ser subdivididos em três grupos principais: brechas, tufos e aglomerados; rochas efusivas e hipoabissais; e rochas plutônicas (FRAENKEL et al., 1985).

- As brechas, tufos e aglomerados correspondem ao material vulcânico aflorante na porção noroeste do maciço, formada na maior parte por tinguaíto com vestígios de lava de ankaratrito.

- As rochas efusivas e hipoabissais são representadas por fonólitos e tinguaítos respectivamente, que segundo Leonardi (2007), os tinguaítos/ fonólitos intrusivos correspondem a $78 \%$ do maciço, as nefelina sientitos a $13,5 \%$, as lavas fonolíticas a $5 \%$ e as vulcanoclásticas a $3 \%$.

- As rochas plutônicas ocorrem como encaixantes para as efusivas e hipoabissais e são constituídas por foiaítos e por lujauritos, ocorrendo também chibinitos em menor proporção (ULBRICH et al., 2002). Segundo Leonardi (2007) os lujauritos e chibinitos correspondem a $0,5 \%$ do maciço.

Outro aspecto importante é a existência de "rocha potássica", resultante da alteração, por processos hidrotermais, e de intemperismo do tinguaíto (FRAENKEL et al., 1985), que constituí importante controle para as mineralizações uraníferas no maciço.

A evolução do modelado recente do relevo, formou grande parte de pequenas bacias, que em sua maioria são preenchidas por depósitos de argila. Alguns desses depósitos já são lavrados para uso na indústria de refratários (LEONARDI, 2007).

A hipótese de que esses depósitos ligados à história mais recente do Planalto, e que necessariamente envolve a mobilização de solos um pouco mais antigos, além da erosão das áreas mais altas atuarem como concentradores de minerais pesados potencialmente portadores de terras raras (tais como zircão, baddeleita, rutilo e ilmenita), ainda não foi investigada.

A avaliação do potencial geológico dessas bacias modernas por vezes associadas a drenagens permanentes e ativas requer análises pormenorizadas amparadas por técnicas de análise litoquímicas e estratigráficas.

Para essa abordagem inédita de pesquisa são consideradas, como mais promissoras, áreas ao redor dos antigos distritos produtores de urânio (arredores da mina Osamu Utsumi), minas atuais de argila refratária e cerâmica (arredores do Marco Divisório), além das ocorrências de baddeleita na região conhecida como Campo das Brígidas.

\section{CONCLUSÃO}

Em Poços de Caldas há um solo ferralítico correspondente a um depósito laterítico na região do Morro do Ferro, que teve, nas décadas de 50 e 60, intensa exploração de terras raras.

A revisão bibliográfica ora apresentada mostra que a demanda mundial para terras raras fomenta e justifica plenamente a investigação do potencial do Planalto de Poços de Caldas para produção desse bem mineral. Devido ao histórico de lavra e registro de escassez de minerais portadores de terras raras, é necessário agora considerar uma nova abordagem, focando depósitos de argilas ligados as fases finais da evolução do maciço, como novas áreas potenciais. 


\section{AGRADECIMENTO}

Os autores agradecem à Fundação de Amparo à Pesquisa do Estado de Minas Gerais FAPEMIG e a Pró - Reitoria de Pesquisa e Pós - Graduação da Universidade Federal de Alfenas UNIFAL - MG pelo apoio à realização do projeto e participação no XXIV - ENTMME.

\section{REFERÊNCIAS BIBLIOGRÁFICAS}

1. ABRÃO, A. Química e tecnologia das terras-raras. Série Tecnologia Mineral No66. CETEM/CNPQ, 212p, 1994.

2. ABREU, V. A. Investigação Prospectiva das Indústrias dos Terras Raras - Subsidio para Políticas e Gestão em Minerais/ Materiais Estratégicos, Campinas, 1991.

3. ANDRADE, R. H. P. de. Terras raras. Sumário Mineral, DNPM - Departamento Nacional de Produção Mineral. ISSN 0101-2053. Brasília, DF, vol. 31, 2011, p. 89-90.

4. BIRKETT, T. C. et al. Carbonatite-associated Deposits: Magmatic, Replacement and Residual; in Simandl, G.J. et al. Selected British Columbia Mineral Deposit Profiles, Volume 3, Industrial Minerals. Lefebure Editors, British, Columbia. Ministry of Energy and Mines, 1999, 137 p.

5. FRAENKEL, M.O.; SANTOS, R.C.; LOUREIRO, F.E.V.L. \& MUNIZ, W.S. Jazida de Urânio do Planalto Poços de Caldas, Minas Gerais. In: SCHOBBENHAUS, C. \& COELHO, C.E.S., coords. Principais depósitos minerais do Brasil. Brasília, DNPM/CVRD, 1985. v.1. p.89-103.

6. HUMPHRIES, M. Rare Earth Elements: The Global Supply Chain. In: Congressional Research Service, 7-5700, 2012, $31 \mathrm{p}$.

7. IUPAC - International Union for Pure and Applied Chemistry. Disponível em: http://www.iupac.org/. Acesso em 20 de jun. 2012.

8. LAPIDO- LOUREIRO, F. E. V. Terras Raras no Brasil-Depósitos, recursos identificados, reservas. Rio de Janeiro, CETEM, 1994, p. 10-39.

9. LAPIDO-LOUREIRO, F. E. Terras-Raras: Tipos de Depósitos, Recursos Identificados e Alvos Prospectivos no Brasil. In: SEMINÁRIO BRASILEIRO DE TERRAS RARAS, 1ㅇ, 2011, Rio de Janeiro. Bases para o desenvolvimento de Terras raras no Brasil. Rio de Janeiro: CETEM - CENTRO DE TECNOLOGIA MINERAL, 2011, 33 p.

10. LEONARDI, F. A. A relação dos perfis lateríticos bauxíticos com as superfícies geomórficas do planalto de Poços de Caldas SP/MG, 2007, 156 p.

11. MORAES, F. T.; Jiménez-Rueda, J. R. Fisiografia da região do planalto de Poços de Caldas, MG/SP. Rev. bras. geociênc., São Paulo, v. 38, n. 1, mar. 2008.

12. MOREIRA, F. R. S. et al. Spatial Analysis techniques applied to mineral prospecting: an evaluation in the Poços de Caldas Plateau. Rev. bras. geociênc., vol. 33, n. 2 -Suplemento, jun. 2003. p. 183 - 190.

13. NEUMANN, H. et al. Distribution patterns of rare earth elements in minerals. Rev. nor. geológ., v. 50,1966, p. 357-373.

14. PETRICK, A. J. R. et al. The economics of byproduct metals: lead, zinc, uranium, rare earth, iron, aluminium, titanium and a lithium system. Washington: Bureau of Mines, 1973. 
15. SLAVEC, G. B. et al. Estudo gravimétrico do maciço alcalino de poços de caldas. Revista Brasileira de Geociências, vol. 34, 2004, 6 p.

16. TSE, Pui-Kwan. China's Rare-Earth Industry. U. S. Geological Survey. Open-File Report 20111042, Reston, Virginia, 2011. 11 p.

17. ULBRICH, H.H.G.J et al. Penecontemporaneous syenitic-phonolitic and basic-ultrabasiccarbonatitic rocks at the Poços de Caldas Alkaline Massif, SE Brazil: geologic and geochronologic evidence. Rev. bras. geociênc., vol. 32, n. 1, pag. 15-2 